Marquette University

e-Publications@Marquette

College of Nursing Faculty Research and

Publications

Nursing, College of

$12-1-2018$

\title{
Depression, Positive Thinking, Personal and Social Resourcefulness among Caregivers of Persons with Autism Spectrum Disorders
}

Abir K. Bekhet

Marquette University, abir.bekhet@marquette.edu

Mauricio Garnier-Villarreal

Marquette University, mauricio.garniervillarreal@marquette.edu

Accepted version. Archives of Psychiatric Nursing, Vol. 32, No. 6 (December 2018): 823-827. DOI. (C) 2018 Elsevier B.V. Used with permission. 
Marquette University

\title{
e-Publications@Marquette
}

\section{Nursing Faculty Research and Publications/College of Nursing}

This paper is NOT THE PUBLISHED VERSION; but the author's final, peer-reviewed manuscript.

The published version may be accessed by following the link in the citation below.

Archives of Psychiatric Nursing, Vol. 32, No. 6 (December, 2018) : 823-827. DOI. This article is (C) Elsevier (WB Saunders) and permission has been granted for this version to appear in ePublications@Marquette. Elsevier (WB Saunders) does not grant permission for this article to be further copied/distributed or hosted elsewhere without the express permission from Elsevier (WB Saunders).

\section{Depression, Positive Thinking, Personal and Social Resourcefulness Among Caregivers of Persons with Autism Spectrum Disorders}

\author{
Abir K. Bekhet \\ Marquette University College of Nursing, Milwaukee, WI \\ Mauricio Garnier-Villarreal \\ Marquette University College of Nursing, Milwaukee, WI \\ Highlights \\ - Caregivers of persons with ASD are prone to depression and psychological problems. \\ - Depression has a negative correlation with positive thinking, personal, and \\ social resourcefulness. \\ - Positive thinking has mediating effects on personal resourcefulness. \\ - Positive cognitions interventions for caregivers are highly needed and recommended.
}


One in sixty-eight children are affected by autism spectrum disorders (ASD). ASD is a neurological developmental disability that can negatively impact the person's communication, social interactions, and is manifested by repetitive behaviors (Baker \& Jeste, 2015; National Autism Association, 2014). Over three-quarters of children with ASD have some sort of developmental disorders such as language disorders and/or attention deficit hyperactivity disorders (Levy et al., 2010), in addition to co-morbid psychiatric disorders such as anxiety disorders, bipolar disorders, and oppositional defiant disorders (Close, Lee, Kaufmann, \& Zimmerman, 2012; National Autism Association, 2014). ASD is a lifelong developmental disability that emerges before age three (National Autism Association, 2014). In fact, the rate of ASD diagnoses in the US has shown abrupt increase over the past three decades (Karst \& Van Hecke, 2012). Furthermore, the understanding and conceptualization of ASD is rapidly and perpetually changing (Rutter, 2011). Consequently, families of persons with ASD are faced with a disorder of unclear etiology for which optimal treatment is challenging, all of which might delay accessing services, which could lead to poorer treatment outcomes (Karst \& Van Hecke, 2012). Of note, much of the research that has been done has been devoted toward developing better understanding of biological and genetic markers in hopes to better understand the etiology and manifestation of ASD. However, research designed to help individuals with ASD and their families has been comparatively more limited (Karst \& Van Hecke, 2012).

The impacts on caregivers of having a child with an ASD are multifaceted and pervasive. In fact, cognitive and adaptive limitations are present in over $85 \%$ of persons with ASD, which limits their ability to live independently and thus requires caregiving (Volkmar \& Pauls, 2003). Caregiving of persons with ASD can be demanding and can negatively impact family caregivers' well-being (Bekhet, 2014; Kirby, White, \& Baranek, 2015). Caregivers of Persons with ASD are more prone to depression as compared with parents who have normally developed children (Almansour, Alateeq, Alzahrani, Algeffari, \& Alhomaidan, 2013; Benson, 2006; Ekas, Lickenbrock, \& Whitman, 2010; Strang et al., 2012). Yet some caregivers of persons with ASD develop resilience and report that caregiving results in an enhanced sense of meaning, empowerment, acceptance, and family connectedness (Bayat, 2007; Bekhet \& MatelAnderson, 2017; Benderix, Nordstrom, \& Sivberg, 2006; Phelps, McCammon, Wuensch, \& Golden, 2009). Thus, studies have shown that caregiving is a major experience in a caregiver person's life, which can be viewed positively or negatively by caregivers and consequently might have positive or negative psychological consequences.

\section{Theoretical framework}

Resilience theory provides the theoretical framework for this study and can help explaining different experiences expressed by caregivers (Richardson, 2002). Resilience is a concept that has been used across various disciplines. For example, in physics and engineering, it refers to the ability of the material to return to its original shape (Gillespie, Chaboyer, \& Wallis, 2007; Kobiske \& Bekhet, 2018). In business, it refers to the ability to recover from economic downturns (Earvolino-Ramirez, 2007). In psychology, early writing focused on children and adolescents who become achievers as adults despite adverse childhood experiences (Herrman et al., 2011; Masten, 2011; Zauszniewski, Bekhet, \& Suresky, 2009). Definitions and uses of resilience might vary, but they all share characteristics of overcoming adversity and regaining homeostasis (Earvolino-Ramirez, 2007). Resilience not only can help people to deal with the stress associated with caregiving, but also helps them to thrive and to grow into healthier and stronger persons (Bekhet, Johnson and Zauszniewski, 2012a, Bekhet, Johnson and Zauszniewski, 
2012b; Kobiske \& Bekhet, 2018; Zauszniewski, Bekhet, \& Suresky, 2015). Resilience is the interplay between risk and protective factors in face of adversity that helps to maintain one's stability (American Psychological Association, 2014). Risk factors are stressors that can negatively impact physical and mental health if not well managed (Smith-Osborne, 2007). Risk factors involved in caring for a family member with ASD include caregiver's depression, a serious mental disorder that profoundly impacts quality of life (Yang et al., 2015). Research has shown that more than a third of caregivers of persons with ASD exceeded the cut off scores of clinical depression (Bekhet, 2016; Smith, Seltzer, TagerFlusberg, Greenberg, \& Carter, 2008). Protective factors are characteristics or conditions that promote resilience and buffer the effects of risk factors. A protective factor for family caregivers of persons with ASD that is proposed in this study, is positive thinking. Positive thinking is a cognitive process that helps individuals to deal with stress more effectively. Positive thinking allows the person to look at the positive and negative aspects of an event and then focus on a positive interpretation (Bekhet \& Zauszniewski, 2013; Tod, Warnock, \& Allmark, 2011), recognizing the fact that in many circumstances, one cannot change the situation or event, but one can change the interpretation by focusing on the positive and by reframing one's thoughts. Research has shown that caregivers of persons with ASD who are positive thinkers experienced less stress and enhanced well-being as compared to those with less positive thinking (Bekhet et al., 2012a).

Resourcefulness, an indicator of resilience, is defined as the collection of cognitive and behavioral skills that are necessary to attain and regain health. The construct of resourcefulness is conceptualized in two forms: personal and social resourcefulness. Personal resourcefulness (sometimes referred to as self-help) involves the ability to function independently when facing adversity (Rosenbaum, 1990; Zauszniewski, 2006). Personal resourcefulness skills include: organizing daily activities, positive self-talk, positive reframing, changing from usual reactions, and exploring new ideas. Social resourcefulness (sometimes referred to as help-seeking) includes looking for help from others when one cannot function alone (Zauszniewski, 2006, Zauszniewski, 2012). Social resourcefulness skills include: relying on family and friends, exchanging ideas with others, and seeking professionals or experts. These skills are used to manage adverse thoughts and feelings to enable the persons to perform target behaviors and tasks (Zauszniewski, 2012). Previous research showed that persons with greater resourcefulness had better social role functioning, quality of life, and healthy productive life styles as compared with persons with low resourcefulness (Bekhet, Zauszniewski, \& Wykle, 2008; Zauszniewski, 1994, Zauszniewski, 1995, Zauszniewski, 1996; Zauszniewski \& Martin, 1999). More specifically, older adults with high resourcefulness skills show a more independent, productive life, and have better adjustment to relocation to retirement communities as compared to those with less resourcefulness skills (Bekhet \& Zauszniewski, 2016; Bekhet et al., 2008; Intieri \& Rapp, 1994). Also, previous research has shown that resourcefulness helped persons with chronic illness to better cope with disabilities (Aikens, Wallander, Bell, \& Cole, 1992). Previous studies, however, have not looked at the relationships between caregivers of persons with ASD's depression, personal and social resourcefulness, and positive thinking as proposed in this study.

The study will address the following research questions (Fig. 1):

1. Does depression have direct effects on personal and social resourcefulness?

2. Does positive thinking have direct effects on personal and social resourcefulness?

3. Does depression have a direct effect on positive thinking?

4. Does positive thinking have a mediating effect on personal and social resourcefulness? 


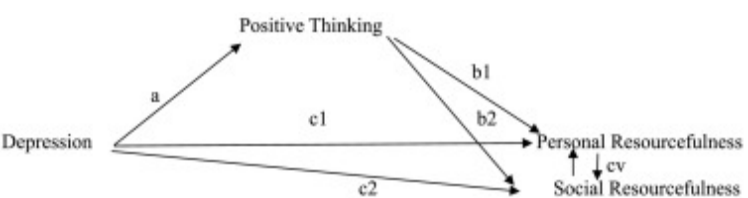

Fig. 1. The research model.

\section{Method}

\section{Design}

The study was a secondary analysis of data from a cross sectional study of 109 ASD caregivers. The parent study was designed to assess the psychometrics of the Positive Thinking Skills Scale.

\section{Sample, setting, and data collection}

In the parent study, the sample included 109 ASD caregivers. Inclusion criteria were: being able to read and understand English, had Internet access, and resided in the US. The institutional review board (IRB) approval was obtained from the university. Participants were recruited by convenience sampling from the Interactive ASD Network (IAN) Research registry service. IAN sent ASD caregivers an IRB approved flyer via e-mail that directed them to an internet website where they accessed the consent form and a link to the study questionnaires. At the end of the survey, the caregivers were offered an option to provide their e-mail addresses if they wished to claim their gift cards. Upon study completion, caregivers were sent a code that could be redeemed for a \$15 amazon gift card (Bekhet \& Zauszniewski, 2013).

\section{Instruments}

Descriptive data concerning ASD caregivers were collected. In addition, measures of positive thinking, resourcefulness, and depression were collected.

Depression was measured by the CES-D (Radloff, 1977). The CES-D is a 20-item measure on a 4point Likert scale ranging from 0 to 3 . The total score may range from 0 to 60 , with higher scores indicating more depressive symptoms. The scale is reliable and valid as indicated by a Cronbach's alpha of 0.92 in mothers of children with ASD (Ekas, Whitman, \& Shivers, 2009). Criterion validity was indicated by significant correlations in the expected direction with the Hamilton Clinician's Rating Scale and with the Raskin Rating Scale (Radloff, 1977).

Resourcefulness was measured by the self-report 28-item Resourcefulness Scale (RS), which measures personal (16 items) and social resourcefulness (12 items) (Zauszniewski et al. 2006). RS is a 6-point Likert scale ranging from 0 to 5 and scores might range from 0 to 140 . The higher the scores on the RS, the higher the personal and social resourcefulness. The scale is reliable as indicated by a Cronbach's alpha of 0.90 (Bekhet \& Garnier-Villarreal, 2017). Confirmatory factor analysis revealed two dimensions of resourcefulness (personal and social) and substantial intercorrelation between the two subscales ( $r=0.41, p<0.001$ ) (Zauszniewski et al. 2006).

Positive thinking was measured by the 8- item Positive Thinking Skills Scale (PTSS) (Bekhet \& Zauszniewski, 2013). PTSS is a 4-point Likert Scale ranging from 0 to 3 and scores might range from 0 to 24 with higher scores indicating more positive thinking. The Scale is reliable as indicated by a Cronbach's alpha of.90 in caregivers of persons with ASD (Bekhet \& Zauszniewski, 2013). Criterion validity was 
indicated by significant correlations with positive cognitions, resourcefulness, and depression in the expected direction (Bekhet \& Zauszniewski, 2013; Bekhet, 2017).

\section{Plan for Data Analysis}

The data analysis was done in $\mathrm{R}$ (R Core Team, 2017). The data analysis approach was using Structural Equation Modeling (SEM), with the R package lavaan (Rosseel, 2012), this framework allows us to reduce measurement error of the instruments, and estimate a more precise measure of the latent factor underlying the scale items (Kline, 2015; Little, 2013; McArdle \& Nesselroade, 2014). Missing data will be handled with Full Information Maximum Likelihood (FIML), a modern method to properly handle missing data, improving parameter recoverability, reducing bias, and increasing power (Baraldi \& Enders, 2010; Enders, 2010).

The reliability was evaluated with the Maximal Reliability (MR) coefficient. MR estimates the reliability of a scale assuming items have a different weight into it. MR is the maximal possible reliability for a linear combination of the scale items. MR involves the estimation of the optimal linear combination (OLC), which are the weights for each item, OLC represents the different item weights for MR. MR measures reliability of a scale, unlike Cronbach alpha which estimate inter-item correlation (Li, 1997; Raykov, 2012). MR is estimated with the R package semTools (semTools Contributors, 2017).

The SEM model includes latent factors for Depression (DEP), Positive Thinking (PT), Personal (PR), and Social Resourcefulness (SR). By using multiple items to approximate the latent factor and correct for measurement error, we achieve more accurate estimates for the parameters of interests as well as the relations between factors (Little, 2013; McArdle \& Nesselroade, 2014). The factors will be defined by parcels of the original items from the scales, the items were averaged into three parcels for each factor (Little, Cunningham, Shahar, \& Widaman, 2002).

Once the latent factors are defined, the mediation model estimated the direct and indirect effects simultaneously in a comprehensive model. For the appropriate estimation of the indirect effects, bootstrap was used as a resampling method (MacKinnon, Fairchild, \& Fritz, 2007; MacKinnon, Lockwood, \& Williams, 2004). The indirect effects are tested by creating an empirical distribution of them based on the bootstrap resamples, these empirical distributions are tested against the null hypothesis value of 0 , the inferences are made in function of the Bootstrap Confidence Intervals. The model was estimated with 5000 bootstrap samples, and estimated with Maximum Likelihood, and the Confidence Intervals $(\mathrm{Cl})$ are presented as the bias corrected $\mathrm{Cl}$. The mediation model includes DEP as the predictor, PT as the mediator, and PR and SR as the outcome factors.

\section{Results}

The sample consists of 109 caregivers of persons with ASD. Their ages ranging from 24 to 58 years of age with an average age of 42 years old $(S D=7.0)$. Most of the caregivers were females $(96.3 \%)$ and Caucasian (88\%). Almost all the sample (98\%) reported living with the person with ASD in the same household, the other $2 \%$ reported living with the person with ASD part of the time.

Table 1 presents the reliability estimates for the factors in the model. All Maximal Reliability (MR) estimates are above 0.87 , indicating high reliability for every factor. The first step is to estimate the Confirmatory Factor Analyses (CFA), which presents good model fit $\left(X^{2}(48)=71.26, p=0.016\right.$, $\mathrm{CFI}=0.967, \mathrm{TLI}=0.955, \mathrm{RMSEA}=0.067[90 \% \mathrm{Cl}=0.029,0.098], \mathrm{SRMR}=0.048$, gamma-hat $=0.965)$. For 
every factor loading we reject the null hypothesis of them being equal to $0(p<0.001)$, and all standardized factor loading are above 0.75 , meaning that the latent factors explained at least $56 \%$ of the variance in the indicator parcels.

Table 1. Maximal reliability.

\begin{tabular}{|l|l|}
\hline Latent factor & MR \\
\hline Positive thinking & 0.922 \\
\hline Depression & 0.947 \\
\hline Personal resourcefulness & 0.903 \\
\hline Social resourcefulness & 0.871 \\
\hline
\end{tabular}

Table 2 shows the correlations between factors, as expected depression has a negative correlation with the other three factors, while every other correlation is positive. All correlations present a medium strength, while PT-PR and DEP-SR present a large effect.

Table 2. Correlations between latent factors.

\begin{tabular}{|l|l|l|l|l|}
\hline & PT & DEP & PR & SR \\
\hline PT & 1 & & & \\
\hline DEP & $-0.394^{*}$ & 1 & & \\
\hline PR & $0.843^{*}$ & $-0.356^{*}$ & 1 & \\
\hline SR & $0.333^{*}$ & $-0.536^{*}$ & $0.511^{*}$ & 1 \\
\hline
\end{tabular}

$* p<0.005$.

The mediation model includes the direct effect of DEP on PR (c1), and SR (c2), direct effect of PT on PR (b1), and SR (b2), and the direct effect of DEP on PT (a). The indirect effects are estimated as the product of direct effects, so the indirect effect of DEP on PR though PT is $a^{*} b 1$, and the indirect effect of DEP on SR through PT is $a^{*} b 2$. With this model, we can also estimate the total effect of DEP on PR and SR, these are the sum of the direct and indirect effects $(a * b 1+c 1$, and $a * b 2+c 2$ respectively). This allows to also include the difference between indirect effects $\left(a^{*} b 1-a^{*} b 2\right)$, and the difference between total effects $\left(a * b 1+c 1-a^{*} b 2+c 2\right)$. With these differences we can identify which path has a stronger impact in the outcome factors.

The results of the mediation model are presented on Table 3, the standard errors, and Confidence Intervals are based on the bootstraps. We can see from the direct effects, we reject the null hypothesis of them being equal to 0 for most of them, except DEP $\rightarrow$ PR, and PT $\rightarrow$ SR. For the indirect effects we found that one of them is different from 0 (DEP $\rightarrow P T \rightarrow P R$ ), as well as both total effects are different from 0 . From the differences, we find that we find the indirect effects not being equal, and the total effects are equal.

Table 3. Mediation model.

\begin{tabular}{|l|l|l|l|l|}
\hline Parameter & Label & Estimate (SE) & $\mathbf{9 5 \% ~ C l}$ & Standardized \\
\hline DEP $\rightarrow$ PT & a & $-0.429(0.143)$ & $-0.719,-0.162$ & -0.394 \\
\hline DEP $\rightarrow$ PR & c1 & $-0.052(0.186)$ & $-0.407,0.325$ & -0.028 \\
\hline DEP $\rightarrow$ SR & c2 & $-0.575(0.212)$ & $-1.023,-0.205$ & -0.480 \\
\hline PT $\rightarrow$ PR & b1 & $1.424(0.291)$ & $0.980,2.062$ & 0.832 \\
\hline PT $\rightarrow$ SR & b2 & $0.158(0.145)$ & $-0.131,0.438$ & 0.144 \\
\hline PR $\leftrightarrow$ SR & cV & $0.489(0.162)$ & $0.131,0.771$ & 0.489 \\
\hline
\end{tabular}




\begin{tabular}{|c|c|c|c|c|}
\hline DEP $\rightarrow$ PT $\rightarrow$ PR & $a * b 1$ & $-0.611(0.229)$ & $-1.102,-0.220$ & -0.328 \\
\hline $\mathrm{DEP} \rightarrow \mathrm{PT} \rightarrow \mathrm{SR}$ & $a * b 2$ & $-0.068(0.064)$ & $-0.206,0.047$ & -0.057 \\
\hline Total PR & $a * b 1+c 1$ & $-0.663(0.274)$ & $-1.219,-0.148$ & -0.356 \\
\hline Total SR & $a * b 2+c 2$ & $-0.643(0.189)$ & $-1.047,-0.313$ & -0.536 \\
\hline Difference Indirect & $a * b 1-a * b 2$ & $-0.543(0.229)$ & $-1.056,-0.175$ & -0.271 \\
\hline Difference total & $a * b 1+c 1-a * b 2+c 2$ & $-0.020(0.263)$ & $-0.523,0.508$ & 0.180 \\
\hline
\end{tabular}

The results indicate that DEP has an effect on PR, but this effect happens only through PT in the indirect effect. While the effect of DEP on SR happens only as a direct effect, with no meaningful indirect effect through PT. This is clear when we compare the total effects, there is no difference between total effects, but for PR only the indirect effect is relevant, and for SR only the direct effect is meaningful, while the total effect of DEP on PR and SR is equivalent, the process on how it affects them differs. And as part of this, there is a meaningful difference between indirect effects, since there is only one relevant indirect effect, on PR through PT.

The direction of the meaningful paths shows that as DEP increases PT and SR decreases with a medium effect size; as PT increases PR increases with a large effect size, this is related to the direct effects. For the indirect effect, as DEP increases, leads to a decrease in PT, while PT has a positive effect on PR, with a medium effect size. The indirect effect shows that as DEP increase lead to a decrease in PR.

Looking at overall impact with the $\mathrm{R}^{2}$, DEP explained $15.5 \%$ of the variance in PT only through its direct effect. While for SR, both DEP and PT explained $30.5 \%$ of its variance, this though their direct and indirect effects. For PR we found the larger impact, since DEP and PT explained $71.2 \%$ of its variance, both through their direct and indirect effects.

Finally, looking at the residual correlation between PR and SR, we find that the information of PR and SR that is not explained by the model still shows medium to large positive correlation between them $(r=0.489)$.

\section{Discussion}

This study investigated the mediating effects of positive thinking, using the positive thinking skills scale, on personal and social resourcefulness among caregivers of persons with ASD. The results of the study indicated that depression has a negative correlation with positive thinking, personal, and social resourcefulness in this sample of 109 caregivers of persons with ASD. The results of the study, are similar, in part with the results of the study conducted by Yang and Colleagues that showed that resourcefulness correlated significantly and negatively with both depressive symptoms and selfharm behaviors in adolescents (Yang, Lai, Yen, Hsu, \& Zauszniewski, 2017). Also, consistent with the results of the study conducted by Musil and colleagues that indicated that fewer depressive symptoms were significantly associated with greater subjective support and higher resourcefulness in grandchildren (Musil et al., 2017).

The results of the current study also indicated that depression has an effect on personal resourcefulness through positive thinking. In other words, positive thinking has mediating effects on personal resourcefulness. The results are consistent with previous research that shows that positive cognitions have a mediating effect on resourcefulness among dementia caregivers (Bekhet, 2013), and mediating 
effects on resourcefulness and sense of coherence in family caregivers of persons with serious mental illness (Zauszniewski et al., 2009).

Also, the results showed that as positive thinking increases, personal resourcefulness increases, which is similar to the results of the study by Wang and Zauszniewski that showed that preadolescent children's resourcefulness was greatly influenced by their cognitive perception (Wang \& Zauszniewski, 2017), and that positive cognitions has a direct positive effect on resourcefulness among older adults who relocated to retirement communities (Bekhet et al., 2008).

The study has several limitations. First, the convenience sample of ASD caregivers who uses the internet, limit the generalizability of the study findings across all ASD caregivers. Second, the study was a secondary analysis of a cross sectional parent study, which made it difficult to assess the positive thinking and resourcefulness variables overtime. Despite these limitations, the study has implications for practice. The results of the study indicated that caregivers of persons with ASD can benefit from a positive thinking training intervention that will impact their personal and social resourcefulness and impact their levels of depression. The Positive Thinking Skills Scale (PTSS) is a brief 8 item scale that measures the frequency of use of eight positive thinking skills and can be used as a screening measure as determined by a cut off score of 13 . Those who score 13 or below needs early intervention, to prevent the development of clinical depression (Bekhet \& Garnier-Villarreal, 2017; Bekhet \& Zauszniewski, 2013). The PTT intervention used mnemonic strategies to facilitate retention and recall namely, acronym and chunking. The acronym "THINKING" will help caregivers to recall the eight positive thinking skills as follow: Transforming negative thoughts into positive thoughts, Highlighting positive aspects of the situation, Interrupting pessimistic thoughts by using relaxation techniques and distraction, Noting the need to practice positive thinking, Knowing how to break a problem into smaller parts to be manageable, Initiating optimistic beliefs with each part of the problem, Nurturing ways to challenge pessimistic thoughts, Generating positive feelings by controlling negative thoughts (Bekhet \& Zauszniewski, 2013; Thornton \& Conway, 2013). Thinking also is a chunk of ideas for caregivers to remember.

Future research might consider using a pretest posttest experimental design to measure the impact of a positive thinking training intervention on caregivers' depression and resourcefulness. A longitudinal study will be beneficial in assessing the immediate, as well as the extended effects of the intervention. This can include measuring the immediate effects of the intervention and measuring the extended effects after 3 months, 6 months, and one year to get a clear picture of the impacts of the intervention on the outcome measures over time. Also, a more diverse sample from different ethnic and culture backgrounds is recommended.

\section{Acknowledgement}

The parent study was funded by Way Klinger Young Scholar Award awarded to Dr. Abir k. Bekhet.

\section{References}

Aikens, Wallander, Bell and Cole, 1992 J.E. Aikens, J.L. Wallander, D.S. Bell, J.A. Cole. Daily stress variability, learned resourcefulness, regimen adherence, and metabolic control in type I diabetes mellitus: Evaluation of a path model. Journal of Consulting and Clinical Psychology, 60 (1) (1992), pp. 113-118 
Almansour, Alateeq, Alzahrani, Algeffari and Alhomaidan, 2013.

M.A. Almansour, M.A.Alateeq, M.K. Alzahrani, M.A. Algeffari, H.T. Alhomaidan. Depression and anxiety among parents and caregivers of autistic spectral disorder children.

Neurosciences, 18 (1) (2013), pp. 58-63

American Psychological Association, 2014 American Psychological Association. The road to resilience. Washington, DC. (Retrieved from). http://www.apa.org/helpcenter/road-resilience.aspx (2014)

Baker and Jeste, 2015 E. Baker, S.S. Jeste. Diagnosis and management of autism spectrum disorder in the era of genomics. Pediatric Clinics of North America, 62 (3) (2015), pp. 607-618

Baraldi and Enders, 2010 A.N. Baraldi, C.K. Enders. An introduction to modern missing data analyses. Journal of School Psychology, 48 (1) (2010), pp. 5-37, 10.1016/j.jsp.2009.10.001

Bayat, 2007 M. Bayat. Evidence of resilience in families of children with autism. Journal of Intellectual Disability Research, 51 (2007), pp. 702-714

Bekhet et al., 2008 A. Bekhet, J.A. Zauszniewski, M. Wykle. Milieu Change and Relocation Adjustment in Elders. Western Journal of Nursing Research, 30 (1) (2008), pp. 113-129

Bekhet, 2013 A. Bekhet. Effects of positive cognitions and resourcefulness on caregiver burden among caregivers of persons with dementia. International Journal of Mental Health Nursing, 22 (2013), pp. 340-346

Bekhet, 2014 A. Bekhet. Self-assessed health in caregivers of persons with autism: Associations with depressive symptoms, positive cognitions, resourcefulness, and well-being. Perspectives in Psychiatric Care, 50 (2014), pp. 210-217

Bekhet, 2017 A. Bekhet. Positive Thinking Training Intervention for Caregivers of Persons with Autism: Establishing Fidelity. Archives of Psychiatric Nursing, 31 (3) (2017), pp. 306-310

Bekhet and Garnier-Villarreal, 2017 A. Bekhet, M. Garnier-Villarreal. The Positive Thinking Skills Scale: A screening measure for early identification of depressive thoughts. Applied Nursing Research, 38 (2017), pp. 5-8

Bekhet and Zauszniewski, 2013 A. Bekhet, J. Zauszniewski. Measuring use of positive thinking skills scale: Psychometric testing of a new scale. Western Journal of Nursing Research, 35 (8) (2013), pp. 1074-1093

Bekhet, 2016 A.K. Bekhet. The mediating effects of positive cognitions on autism caregivers' depression and their children challenging behaviors. Archives of Psychiatric Nursing, 30 (2016), pp. $13-18$

Bekhet, Johnson and Zauszniewski, 2012a A.K. Bekhet, N.L. Johnson, J.A. Zauszniewski. Effects on resilience of caregivers of persons with autism spectrum disorder: The role of positive cognitions. Journal of the American Psychiatric Nurses Association, 18 (6) (2012), pp. 337-344

Bekhet, Johnson and Zauszniewski, 2012b A.K. Bekhet, N.L. Johnson, J.A. Zauszniewski. Resilience in family members of persons with autism spectrum disorder: A review of the literature. Issues in Mental Health Nursing, 33 (10) (2012), pp. 650-656

Bekhet and Matel-Anderson, 2017 A.K. Bekhet, D. Matel-Anderson. Risk and protective factors in the lives of caregivers ofpersons with autism: Caregivers' perspectives. Perspectives in Psychiatric Care, 53 (3) (2017), pp. 199-207

Bekhet and Zauszniewski, 2016 A.K. Bekhet, J.A. Zauszniewski. The effect of a resourcefulness training intervention on relocation adjustment and adaptive functioning among older adults in retirement communities. Issues in Mental Health Nursing, 37 (3) (2016), pp. 182-189 
Benderix, Nordstrom and Sivberg, 2006 Y. Benderix, B. Nordstrom, B. Sivberg. Parents' experience of having a child with autism and learning disabilities living in a group home. Autism: The International Journal of Research \& Practice, 10 (2006), pp. 629-640

Benson, 2006 P. Benson. The impact of symptoms severity of depressed mood among parents of children with ASD. Journal of Autism and Developmental Disorders, 36 (2006), pp. 685-695

Close, Lee, Kaufmann and Zimmerman, 2012 H.A. Close, L. Lee, C.N. Kaufmann, A.W.Zimmerman. Cooccurring conditions and change in diagnosis in autism spectrum disorders. Pediatrics, 129 (2) (2012)

Earvolino-Ramirez, 2007 M. Earvolino-Ramirez. Resilience: A concept analysis. Nursing Forum, 42 (2) (2007), pp. 73-82

Ekas et al., 2009 N.V. Ekas, T.L. Whitman, C. Shivers. Religiosity, spirituality, and socioemotional functioning in mothers of children with autism spectrum disorder. Journal of Autism and Developmental Disorders, 39 (2009), pp. 706-719

Ekas, Lickenbrock and Whitman, 2010 N.V. Ekas, D.M. Lickenbrock, T.L. Whitman. Optimism, social support, and well-being in mothers of children with autism spectrum disorder. Journal of Autism and Developmental Disorders, 40 (2010), pp. 1274-1284

Enders, 2010 C.K. Enders. Applied missing data analysis. Guilford Press, New York (2010)

Gillespie, Chaboyer and Wallis, 2007 B. Gillespie, W. Chaboyer, M. Wallis. Development of a theoretically derived model of resilience through concept analysis. Contemporary Nurse, 25 (2007), pp. 124-135

Herrman et al., 2011 H. Herrman, D. Stewart, N. Diaz-Granados, E. Berger, B. Jackson, T. Yuen. What is resilience. The Canadian Journal of Psychiatry, 56 (5) (2011), pp. 258-265

Intieri and Rapp, 1994 R.C. Intieri, S.R. Rapp. Self-control skillfulness and caregiver burden among helpseeking elders. Journal of Gerontology, 49 (1) (1994), pp. 19-23

Karst and Van Hecke, 2012 J.S. Karst, A.V. Van Hecke. Parent and family impact of autism spectrum disorders: A review and proposed model for intervention evaluation. Clinical Child and Family Psychology Review, 15 (3) (2012), pp. 247-277

Kirby, White and Baranek, 2015 A.V. Kirby, T.J. White, G.T. Baranek. Caregiver strain and sensory features in children with autism spectrum disorder and other developmental disabilities. American Journal on Intellectual and Developmental Disabilities, 120 (1) (2015), pp. 32-45

Kline, 2015 R.B. Kline. Methodology in the social sciences: Principles and practice of structural equation modeling. (5th ed), Guilford, New York, NY (2015)

Kobiske and Bekhet, $2018 \mathrm{~K}$. Kobiske, A. Bekhet. Resilience in caregivers of partners with young onset dementia: A concept analysis. Jan Issues in Mental Health Nursing, 25 (2018), pp. 19, 10.1080/01612840.2017.1400625

Levy et al., 2010 S.E. Levy, E. Giarelli, L.C. Lee, L.A. Schieve, R.S. Kirby, C. Cunniff, ..., C.Rice. Autism spectrum disorder and co-occurring developmental, psychiatric, and medical conditions among children in multiple populations of the United States. Journal of Developmental and Behavioral Pediatrics (4) (2010), pp. 267-274

$\mathrm{Li}, 1997 \mathrm{H}$. Li. A unifying expression for the maximal reliability of a linear composite.

Psychometrika, 62 (1997), pp. 245-249

Little, 2013 T.D. Little. Longitudinal structural equation modeling. Methodology in the social sciences, The Guilfors Press, New York, NY (2013) 
Little, Cunningham, Shahar and Widaman, 2002 T.D. Little, W.A. Cunningham, G. Shahar, K.F. Widaman. To parcel or not to parcel: Exploring the question, weighing the merits. Structural Equation Modeling, 9 (2) (2002), pp. 151-173

MacKinnon, Fairchild and Fritz, 2007 D.P. MacKinnon, A.J. Fairchild, M.S. Fritz. Mediation analysis. Annual Review of Psychology, 58 (1) (2007), pp. 593-

614, 10.1146/annurev.psych.58.110405.085542

MacKinnon, Lockwood and Williams, 2004 D.P. MacKinnon, C.M. Lockwood, J. Williams. Confidence limits for the indirect effect: Distribution of the product and resampling methods. Multivariate Behavioral Research, 39 (1) (2004), pp. 99-128, 10.1207/s15327906mbr3901_4

Masten, 2011 A.S. Masten. Resilience in children threatened by extreme adversity: Frameworks for research, practice, and translational synergy. Development and Psychopathology, 23 (2) (2011), pp. 493-506

McArdle and Nesselroade, 2014 J.J. McArdle, J.R. Nesselroade. Longitudinal data analysis using structural equation models. American Psychological Association, Washington, DC (2014)

Musil et al., 2017 C.M. Musil, H.M. Rice, M. Singer, S.E. Givens, C.B. Warner, J.A.Zauszniewski, et al. Grandchildren's depressive symptoms and perceptions of family functioning: Protective and influencing factors. Western Journal of Nursing Research (2017), Article 193945917721017, 10.1177/0193945917721017.([Epub ahead of print])

National Autism Association, 2014 National Autism Association. Autism fact sheet. (Retrieved from). http://nationalautismassociation.org/resources/autism-fact-sheet/ (2014)

Phelps, McCammon, Wuensch and Golden, 2009 K. Phelps, S. McCammon, K. Wuensch, J.Golden. Enrichment, stress, and growth form parenting an individual with autism spectrum disorder. Journal of Intellectual and Developmental Disability, 34 (2009), pp. 133-141

Radloff, 1977 L.S. Radloff. The -ES-D scale: A self-report depression scale for research in the general population. Applied Psychological Measurement, 1 (1977), pp. 385-401

R Core Team, 2017 R Core Team. R: A language and environment for statistical computing. R Foundation for Statistical Computing, Vienna, Austria (2017). https://www.R-project.org/

Raykov, 2012 T. Raykov. Scale construction and development using structural equation modeling. R.H. Hoyle (Ed.), Handbook of structural equation modeling, Guilford, New York, NY (2012), pp. $472-494$

Richardson, 2002 G.E. Richardson. The metatheory of resilience and resiliency. Journal of Clinical Psychology, 58 (3) (2002), pp. 307-321

Rosenbaum, 1990 M. Rosenbaum. Learned resourcefulness on coping skills, self-control, and adaptive behavior. Springer Publishing Company, New York (1990)

Rosseel, 2012 Y. Rossee. Ilavaan: An R package for structural equation modeling. Journal of Statistical Software, 48 (2) (2012), pp. 1-36. http://www.jstatsoft.org/v48/i02/

Rutter, 2011 M.L. Rutter. Progress in understanding autism: 2007-2010. Journal of Autism and Developmental Disorders, 41 (2011), pp. 395-404

semTools Contributors, 2017 semTools Contributors. semTools: Useful tools for structural equation modeling. $R$ package version 0.4-15.903. (Retrieved from). https://CRAN.Rproject.org/package=semTools (2017)

Smith, Seltzer, Tager-Flusberg, Greenberg and Carter, 2008 L. Smith, M. Seltzer, H. TagerFlusberg, J. Greenberg, A. Carter. A comparative analysis of well-being and coping among 
mothers of toddlers and mothers of adolescents with ASD. Journal of Autism and Developmental Disorders, 38 (5) (2008), pp. 876-889

Smith-Osborne, $2007 \mathrm{~A}$. Smith-Osborne. Life span and resiliency theory: A critical review. Advances in Social Work, 8 (1) (2007), pp. 152-168

Strang et al., 2012 J.F. Strang, L. Kenworthy, P. Daniolos, L. Case, M.C. Wills, A. Martin, G.L.Wallace. Depression and anxiety symptoms in children and adolescents with autism spectrum disorders without intellectual disability. Research in Autism Spectrum Disorder, 6 (1) (2012), pp. 406-412

Thornton and Conway, 2013 M.A. Thornton, A.R. Conway. Working memory for social information: Chunking or domain-specific buffer? Neurolmage, 70 (2013), pp. 233-239

Tod, Warnock and Allmark, 2011 A. Tod, C. Warnock, P. Allmark. A critique of positive thinking for patients with cancer. Nursing Standard, 25 (2011), pp. 43-47

Volkmar and Pauls, 2003 F.R. Volkmar, D. Pauls. Autism. The Lancet, 362 (2003), pp. 1133-1141

Wang and Zauszniewski, 2017 Y.F. Wang, J.A. Zauszniewski. Predictors of resourcefulness in preadolescent children. Western Journal of Nursing Research (2017), 10.1177/0193945917700139. ([Epub ahead of print])

Yang, Lai, Yen, Hsu and Zauszniewski, 2017 F.Y. Yang, C.Y. Lai, C.F. Yen, Y.Y. Hsu, J.A. Zauszniewski. The depressive symptoms, resourcefulness, and self-harm behaviors of adolescents. Journal of Nursing Research, 25 (1) (2017), pp. 41-49

Yang et al., 2015 L. Yang, Y. Zhao, Y. Wang, L. Liu, X. Zhang, B. Li, R. Cui. The effects of psychological stress on depression. Current Neuropharmacology, 13 (4) (2015), pp. 494-504

Zauszniewski, 1994 J.A. Zauszniewski. Health seeking resources and adaptive functioning in depressed and non-depressed adults. Archives of Psychiatric Nursing, 8 (3) (1994), pp. 159-168

Zauszniewski, 1995 J.A. Zauszniewsk. Learned resourcefulness: A conceptual analysis. Issues in Mental Health Nursing, 16 (1) (1995), pp. 13-31

Zauszniewski, 1996 J.A. Zauszniewski. Self-help and help-seeking behavior healthy elders. Journal of Holistic Nursing, 14 (3) (1996), pp. 223-236

Zauszniewski and Martin, 1999 J.A. Zauszniewski, M.H. Martin. Developmental task achievement and learned resourcefulness in healthy older adults. Archives of Psychiatric Nursing, 1 (1999), pp. 41-47

Zauszniewski, 2006 J.A. Zauszniewski. Resourcefulness: A new mid-range theory. J.J. Fitzpatrick, M. Wallace (Eds.), Encyclopedia of nursing research, Springer, New York (2006), pp. 226-258

Zauszniewski, 2012 A. Zauszniewski. Intervention development: assessing critical parameters from the intervention recipient's perspective. Applied Nursing Research, 25 (1) (2012), pp. 31-39

Zauszniewski, Bekhet and Suresky, 2015 J.A. Zauszniewski, A. Bekhet, J. Suresky. Indicators of resilience in family members of adults with serious mental illness. Psychiatric Clinics of North America, 38 (1) (2015), pp. 131-146

Zauszniewski, Bekhet and Suresky, 2009 J.A. Zauszniewski, A. Bekhet, M.J. Suresky. Effects on resilience of women family caregivers of seriously mentally ill adults: The role of positive cognitions. Archives of Psychiatric Nursing, 23 (6) (2009), pp. 412-422 